\title{
Small scale hydropower: generator analysis and optimization for water supply systems
}

\author{
Guilherme A. Caxaria ${ }^{1, *}$, Duarte de Mesquita e Sousa, ${ }^{2, * *}$, Helena M. Ramos ${ }^{3, * * *}$ \\ ${ }^{1}$ Electrical and Computer Engineering Department, Instituto Superior Técnico, Technical University of Lisbon, \\ Lisbon, Portugal. \\ ${ }^{2}$ Electrical and Computer Engineering Department and CIE $^{3}$, Instituto Superior Técnico, Technical University \\ of Lisbon, Lisbon, Portugal. \\ ${ }^{3}$ Civil Engineering Department and CEHIDRO, Instituto Superior Técnico, Technical University of Lisbon, \\ Lisbon, Portugal. \\ * Av. Rovisco Pais, 1049-001, Lisbon, Portugal ,E-mail: gui.caxaria@gmail.com \\ ** Av. Rovisco Pais, 1049-001, Lisbon, Portugal ,E-mail: duarte.sousa@ist.utl.pt \\ *** Av. Rovisco Pais, 1049-001, Lisbon, Portugal,E-mail: helena.ramos@civil.ist.utl.pt
}

\begin{abstract}
This work focuses on the analysis of the power generation feasibility of both a pump as turbine (PAT) and an experimental propeller turbine, when applied to water supply systems. This is done through an analysis of the electrical generation aspects of the PAT's induction motor and of a permanent magnet DC motor, which was connected to the propeller turbine. The collected data allows for parameter optimization, adequate generator choice and computational modeling. These tests constitute a good sample of the range of applicability of small scale turbines as valid solutions for micro-hydro. It is also possible to consider multiple scenarios, such as rescaling/resizing, for larger turbines and systems, and the use of power electronics for further efficiency enhancing.
\end{abstract}

Keywords: Small-scale hydropower, water supply systems, low power turbines, behavioral analysis

\section{Introduction}

Starting from a scientific research base in the field of hydraulics, the objective of this work is to study the applicability and performance of electrical generators when connected to low power hydro turbines, for use in water supply systems (and others with similar characteristics). The generated power has a broad range of application, namely in the field of decentralized production (either on or off-grid) for use in rural or isolated areas, as well as in urban areas. It is possible to use the generated power to supply devices related with the smallscale industry (e.g. hydro-mechanical systems in pumping stations), communication stations, data acquirement, control or telemetry systems, or even observation posts in isolated areas.

Through the use of computer models, laboratorial tests and prototype analysis, a solution for a certain micro-hydro scheme is chosen. Behavioral analysis is then undertaken, allowing for further generator parameter optimization.

\subsection{Water supply systems}

Water supply systems aren't built with a power generation purpose. However, due to the type of infrastructure which is used for their normal operation (pressure reducing and flow control valves, reservoirs, pumps, and piping), they offer a multitude of power generation scenarios while assuring an almost constant flow rate $24 \mathrm{~h} /$ day. It is then possible to generate power in the following manners: replacing (or assembling a joint installation with) pressure reducing valves; taking advantage of the hours where there's an increased demand for water (hours which coincide with an increase in demand for electrical power); piping water between 
reservoirs, in hours of lower demand, and storing the produced energy. All of these are subject to the installation of adequate equipment in the piping.

\subsection{Micro-hydro turbines}

The existing micro-hydro conversion equipment is based on i mpulse turbines (i.e. Pelton, Turgo, and Cross-flow) and on reaction turbines (i.e. Francis and Kaplan/propeller). Their main problem is the low efficiency values (typically $30 \%$ to $60 \%$ ) that are obtained regarding small scale schemes. In this case optimization is needed, in order to increase their efficiency. This type of work, however, will not be discussed in depth in this document.

The application of commercially available small scale turbines to water supply systems is conditioned by a series of restrictions, namely head, flow, pressure, and the need for piping adaptation, which can make them unsuitable for application in a vast majority of sites. Therefore, it is necessary to optimize and/or develop power generation solutions for water supply systems.

\section{Pump as Turbine (PAT)}

Given the information in the introductory chapter, a PAT was the first of the two solutions that have been considered for power generation in water supply systems. This was due to its simplicity in installation, only requiring small adaptation procedures. In water supply systems, a PAT is to be installed in a bypass circuit.

\subsection{Theoretical considerations}

Pumps as Turbines have, for the past three decades, been tested and considered for microhydro generation. This is due to a number of arguments, those being that PATs are mass produced, for various operating conditions, such as flow, drop, dimensions and rotating speeds. The electromechanical converters that usually equip a PAT are asynchronous machines, optimized for pumping operation, which, as previously mentioned, help to reduce acquisition costs, which, in turn, increase the competitiveness of a PAT in a power generation scenario. Another advantage in the use of a PAT is that its technology is vastly explored and with proven results, adding to the fact that these allow for power values starting at 50W [6]. The main disadvantage in the use of a PAT is that its operation is highly dependent on flow rate, not allowing for medium and high variations of flow. In situations where multiple flow values exist, it is possible to consider the use of two or more PATs [2].

\subsection{Laboratorial testing}

For laboratorial testing, a PAT (WITH $N_{S P T\left(M, M^{3} / S\right)}=21 \mathrm{RPM}$ AND $N_{S P T(M, K W)}=51 \mathrm{RPM}$ ) was acquired, and inserted in a laboratorial system that allowed for head and flow variation, and for grid-connected excitation. The electrical machine that equips the PAT is a six-pole (i.e. with a synchronous speed of $1000 \mathrm{rpm}$ ) $550 \mathrm{~W}$ induction motor. The objective was to test the power generation feasibility of the PAT when connected to the grid (i.e. with no additional equipment, such as capacitors for excitation), along with testing the transient response of the induction machine when a hydraulic transient regime occurred (e.g. the closing of a valve). Also analyzed was the behavior of the PAT under runaway conditions.

\subsubsection{Power generation testing}

Regarding power generation, the results are presentED in Figure 1. Values up to $160 \mathrm{~W}$ (at a flow of $4.41 / \mathrm{s}$ ) were registered. However, due to the fact that the machine was excited 
resorting to the main grid, the excitation required $240 \mathrm{~W}$ of power; this meaning that, in fact, the generator never generated enough power to "counter" the excitation, and thus, the load flow was always done from the grid to the generator.

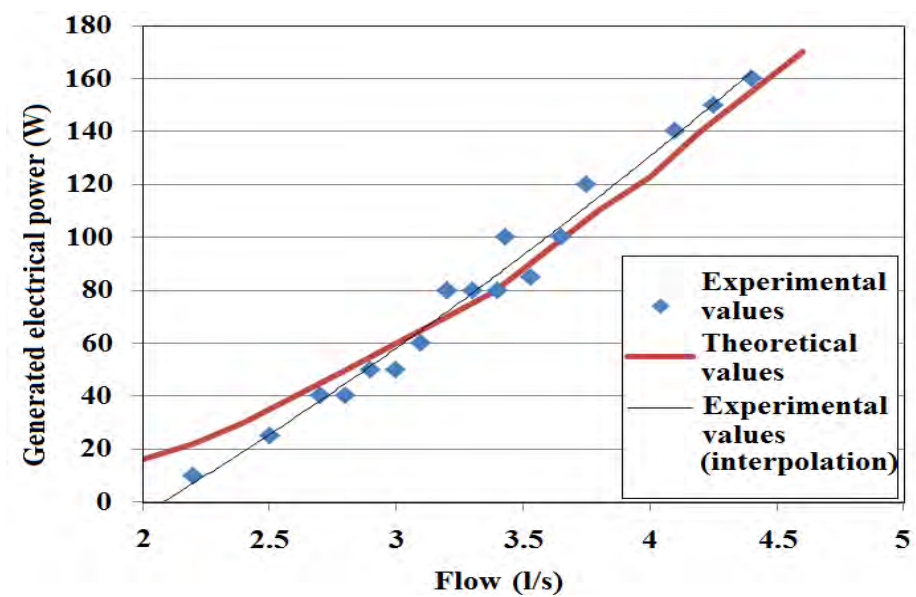

Fig. 1. PAT Power/Flow characteristics.

\subsubsection{Transient response analysis}

Transient analysis, either electrical or hydraulic, at a micro-hydro scale, is a field of research that is rather unexplored. This field of research, however, is of extreme importance, in order to properly dimension electrical protection methods. In this particular case, a h ydraulic transient regime was created by the sudden closure of a valve which, in turn, originated an electrical transient regime. The testing results are presentED in Figure 2.
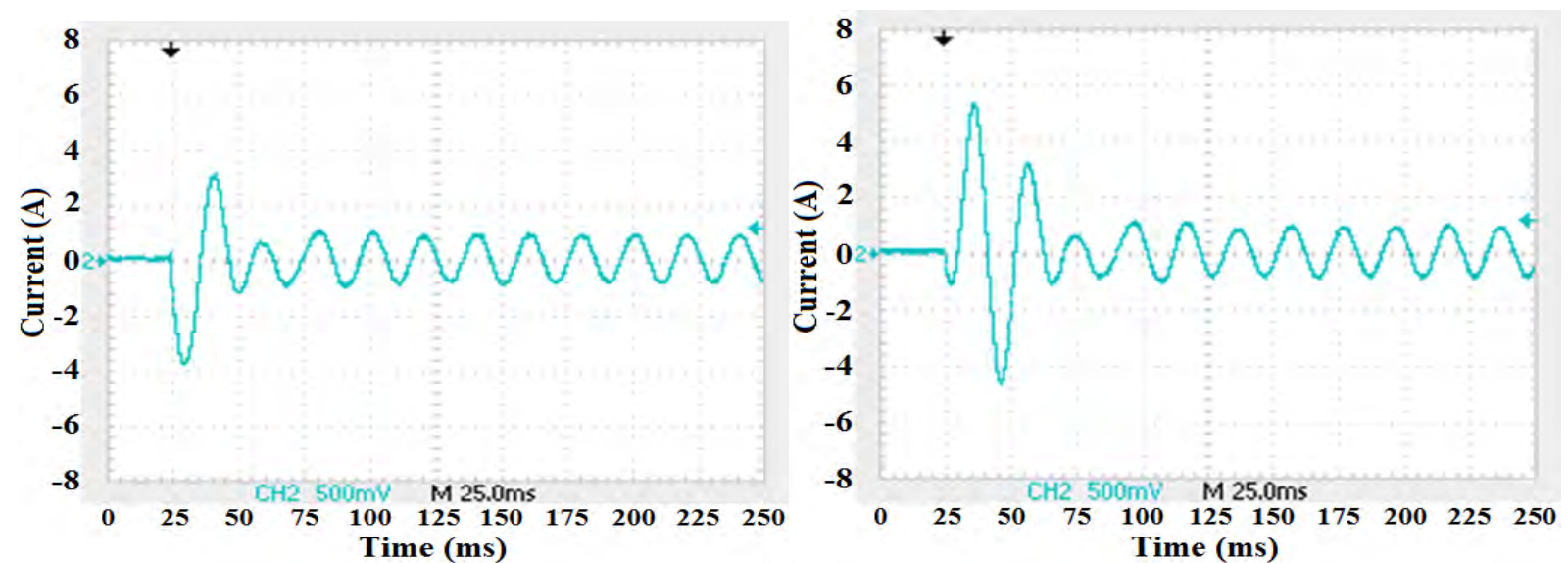

Fig. 2. Electrical transient regimes in the PAT, derived from pressure surges in the piping.

According to the work of [5], it is possible to verify that waterhammer effects induce electrical transients in the generator, thus influencing the power generation. However, it is possible to observe that the duration of the transient regime is, on both cases, under $100 \mathrm{~ms}$. Attending to the values of the time constants that are present in the used hydraulic systems, it is possible to claim that the generator doesn't introduce additional dynamic restrictions to the global system.

\subsubsection{Runaway conditions analysis}

Testing of runaway behavior was also undertaken, in order to properly apply control methods to the system. The results of the mentioned testing are presentED in Figure 3. 


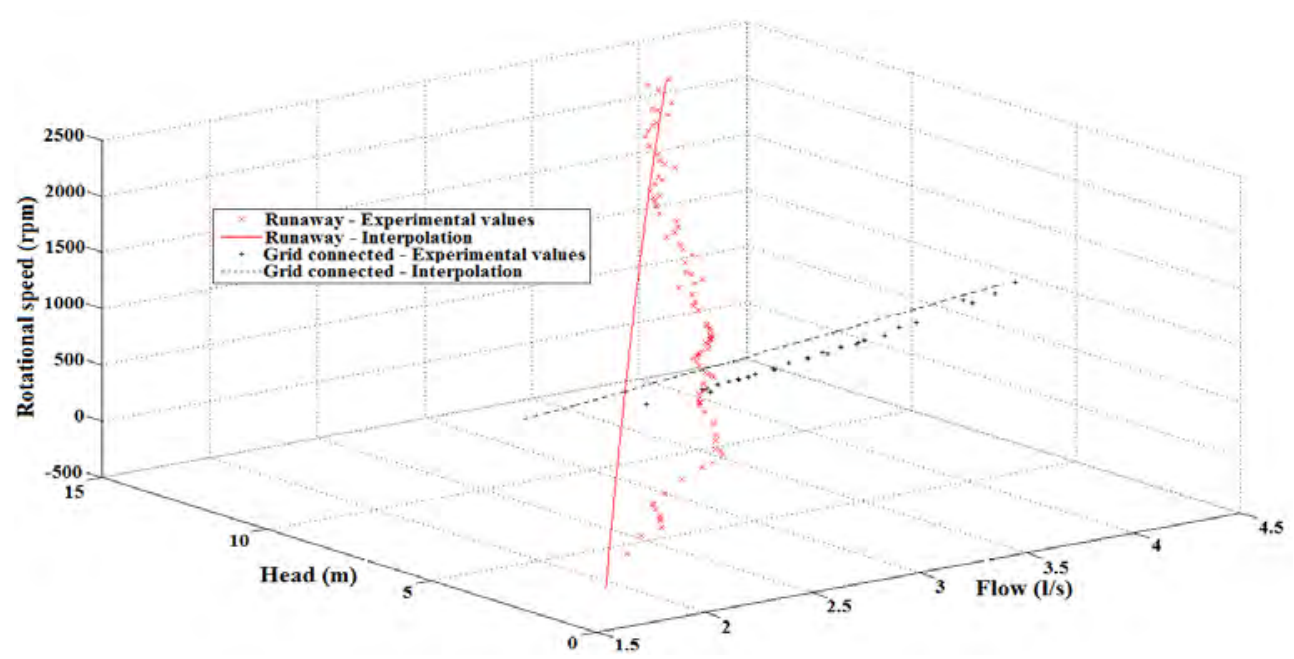

Fig. 3. PAT Runaway and Grid connected operating conditions.

It is possible to observe that, in runaway conditions, for the same flow rate value, pressure surges occur (here described by an increase in the available head). This is coincident with the work of [3] where it is shown that turbines with low specific rotating speeds induce high pressure surges in the piping

\subsection{Computational model: control simulation}

Given the results obtained in laboratorial testing and due to the nature of water supply systems, the chosen (and simulated) control method was the one resorting to flow control valves. The objective of these simulations was to control and avoid a runaway situation, which results from a load withdrawal on the generator. MATLAB/Simulink was used. The control scheme is described in fig 4 and the simulation results are presented in fig 5.

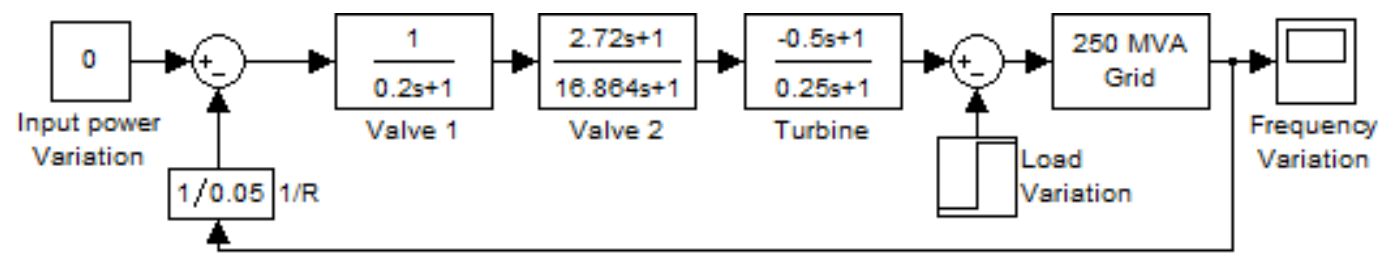

Fig. 4. Control scheme used for the PAT simulations.
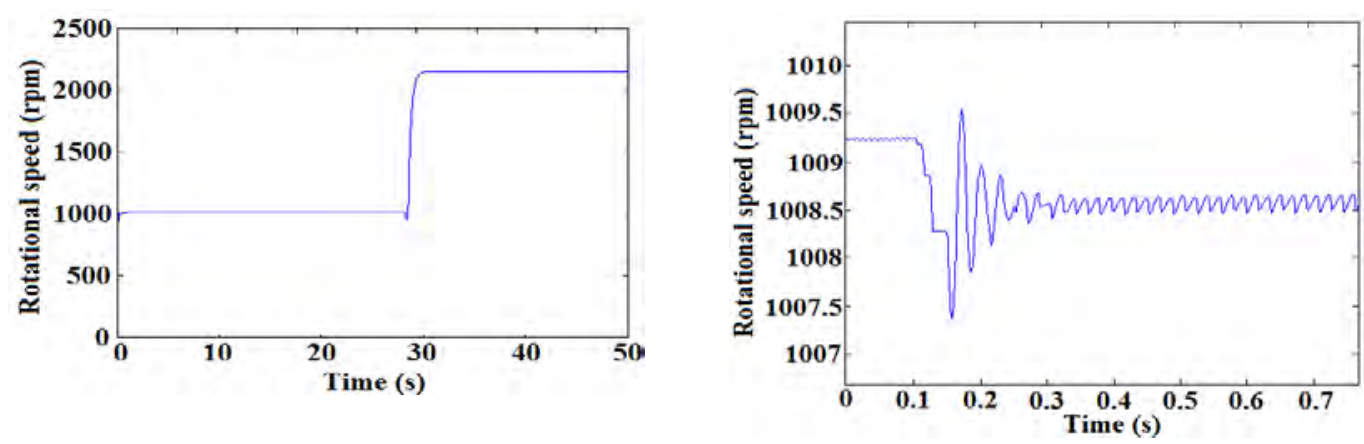

Fig. 5. Simulation results for full and uncontrolled (left), and partial and controlled (right) load removal on the PAT. 


\section{Five blade propeller turbine (5BPT)}

A propeller turbine was the second of the two solutions chosen for micro-hydro generation in water supply systems. Again, equipment and installation simplicity were key factors regarding the choice.

\subsection{Theoretical considerations}

Propeller turbines are axial turbines, adequate for operation under low head (up to a minimum of $1.5 \mathrm{~m})$ and high flow rates. These have been mainly used in small $(<10 \mathrm{MW})$ and mini $(<2 \mathrm{MW})$ hydro schemes. Only recently, due to developments in scientific research (which, in turn, have resulted in an increase of the turbines' efficiency), has the application been extended to the field of micro-hydro.

Given the difficulties on applying commercially available micro-hydro turbines to water supply systems, a $100 \mathrm{~mm}$ diameter prototypical propeller turbine was developed specifically for this purpose (under the HyLow project of the $7^{\text {th }}$ Framework Program of the European Union) and (through the work of [7]) optimized for small scale (i.e. blade shape, number, and orientation). This type of turbine can be installed in either a bypass to, or directly in the main piping circuit. Its main disadvantages are that it is still experimental equipment, and there's very little knowledge regarding its long time operation in water supply systems.

\subsection{Laboratorial testing}

For laboratorial testing, similarly to what was done with the PAT, the 5BPT (with $N_{S P T\left(M, M^{3} / S\right)}=238 \mathrm{RPM}$ AND $\left.N_{S P T(M, K W)}=118 \mathrm{RPM}\right)$ was inserted in a laboratorial system that allowed for head and flow variation, and that mimicked the conditions found on a real water supply system. Being experimental equipment, the maximum obtained speed was of $1550 \mathrm{rpm}$. For power generation purposes a $500 \mathrm{~W}$ DC permanent-magnet machine, derived from an electrical scooter, was acquired. Due to the nature of the generator, and to the lack of additional power electronics, no grid connection was done. The turbine's characteristic curves are shown in Figure 5, the DC machine's characteristics and curves are shown in Table 1 and Figure 6.
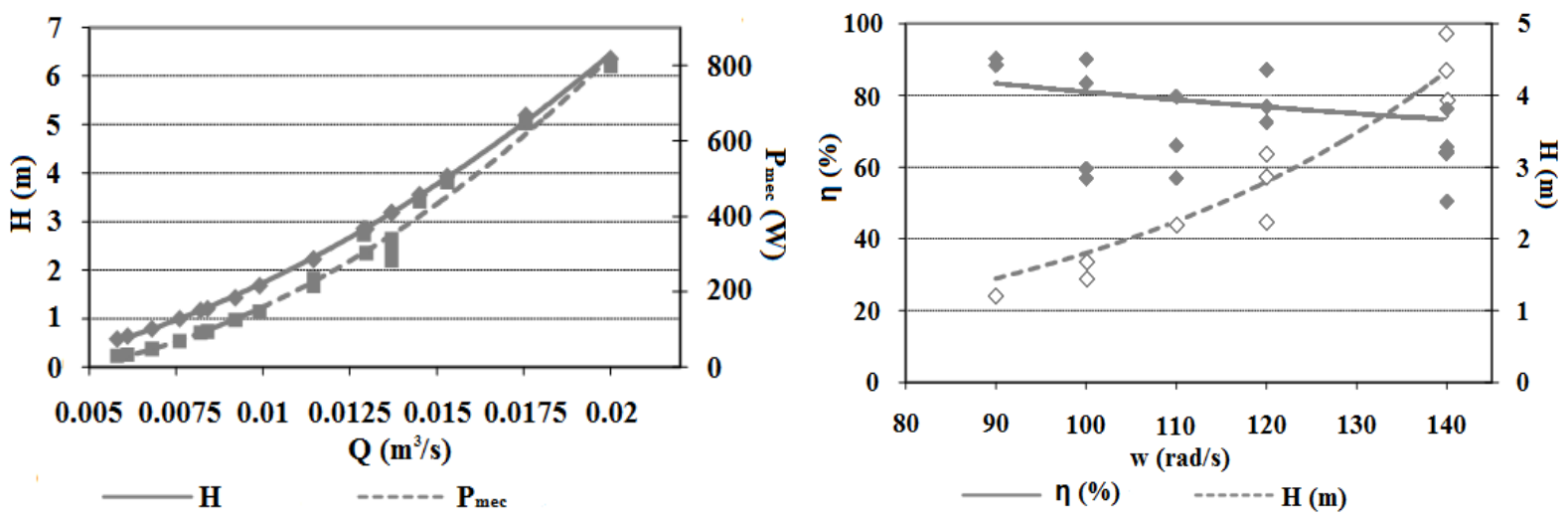

Fig. 6. Five blade propeller turbine characteristic curves

Table 1. DC motor manufacturer's parameters

\begin{tabular}{cccccccc}
\hline $\begin{array}{c}\text { Rated } \\
\text { voltage } \\
(\mathrm{V})\end{array}$ & $\begin{array}{c}\text { Rated } \\
\text { power } \\
(\mathrm{W})\end{array}$ & $\begin{array}{c}\text { No-load } \\
\text { Current } \\
(\mathrm{A})\end{array}$ & $\begin{array}{c}\text { No-load } \\
\text { Speed } \\
(\mathrm{rpm})\end{array}$ & $\begin{array}{c}\text { Rated } \\
\text { Torque } \\
(\mathrm{N} . \mathrm{m})\end{array}$ & $\begin{array}{c}\text { Rated } \\
\text { Speed } \\
(\mathrm{rpm})\end{array}$ & $\begin{array}{c}\text { Rated } \\
\text { Current } \\
(\mathrm{A})\end{array}$ & $\begin{array}{c}\text { Rated } \\
\text { efficiency } \\
(\%)\end{array}$ \\
\hline 36 & 500 & 2.2 & 3150 & 1.9 & 2500 & 17.8 & 78 \\
\hline
\end{tabular}




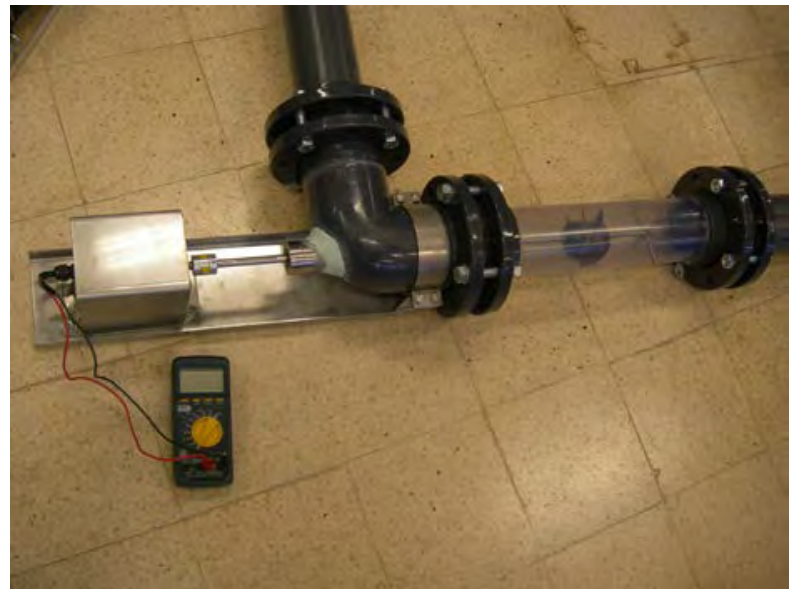

(a)

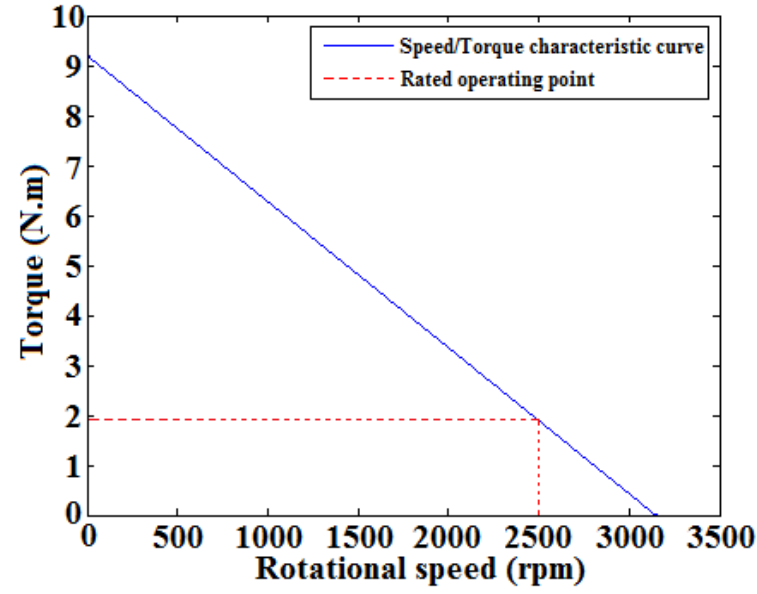

(b)

Fig. 7. (a) The turbine+generator group (b) DC motor manufacturer's Torque/Speed curve.

From the data provided by the manufacturer, it was possible to calculate the machine's theoretical characteristic parameters, namely the armature resistance and the $k_{\phi}$ constant, to be used for computational simulations:

$$
k_{\phi(\text { manufacturer })}=0.1091 \quad R_{a(\text { manufacturer })}=0.4267 \Omega
$$

\subsubsection{Power generation testing}

For power generation testing purposes a $6 \Omega, 16 \mathrm{~A}$ rheostat was used, in order to emulate the behavior of "normal" electrical loads. The testing was done by varying the resistive load while maintaining a fully open admission valve. The testing was done in three separate sessions, being that, on the first session, there was a constraint in terms of head and flow, and on the second and third sessions, that constraint was eliminated. The best efficiency points for the experimental sessions are presentED in Table 2.

Table 2. Best efficiency points for the three experimental sessions.

\begin{tabular}{cccccc}
\hline $\begin{array}{c}\text { Experimental } \\
\text { session }\end{array}$ & $\begin{array}{c}\text { Maximum } \\
\text { Generated } \\
\text { power }(\mathrm{W})\end{array}$ & $\begin{array}{c}\text { Rotational } \\
\text { speed }(\mathrm{rpm})\end{array}$ & $\begin{array}{c}\text { Flow rate } \\
(1 / \mathrm{s})\end{array}$ & $\begin{array}{c}\text { Generator } \\
\text { efficiency } \\
(\%)\end{array}$ & $\begin{array}{c}\text { Overall } \\
\text { efficiency } \\
(\%)\end{array}$ \\
\hline$\# 1$ & 3.64 & 182.5 & 3.6 & 35.6 & 32.8 \\
\hline$\# 2$ & 34.4 & 719.7 & 8.8 & 50.3 & 46.8 \\
\hline$\# 3$ & 36.2 & 619.8 & 10.4 & 68.2 & 60.7 \\
\hline
\end{tabular}

From the testing results, it $\mathrm{w}$ as possible to calculate the machine's real characteristic parameters, and while the armature resistance corresponded to the manufacturer's value, the $k_{\phi}$ constant greatly differed:

$$
k_{\phi(\text { exp erimental })}=0.1443 \quad R_{a(\exp e \text { rimental })}=0.4267 \Omega
$$

\subsubsection{Computational model: power generation simulations}

Given the obtained conclusions regarding the DC machine's characteristic parameters, simulation was undertaken, again using MATLAB/Simulink, in order to test the power generation under optimal conditions (i.e. with $k_{\phi}=k_{\phi(\text { manufacturer })}$ ). Due to the nature (i.e. size) 
of the turbine, a transfer function similar to the Pat's was used. The simulation results are presented in figures 7 and 8 .

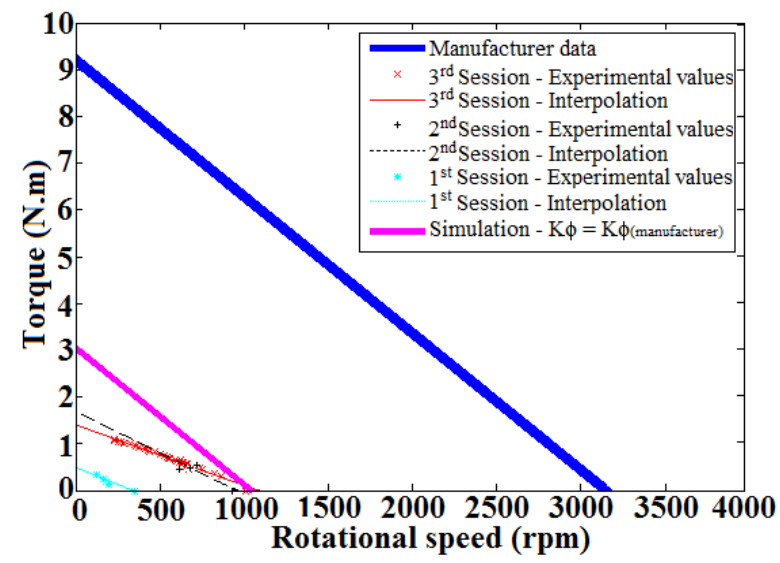

Fig. 8. Manufacturer's, experimental, and simulation Torque/Speed curves

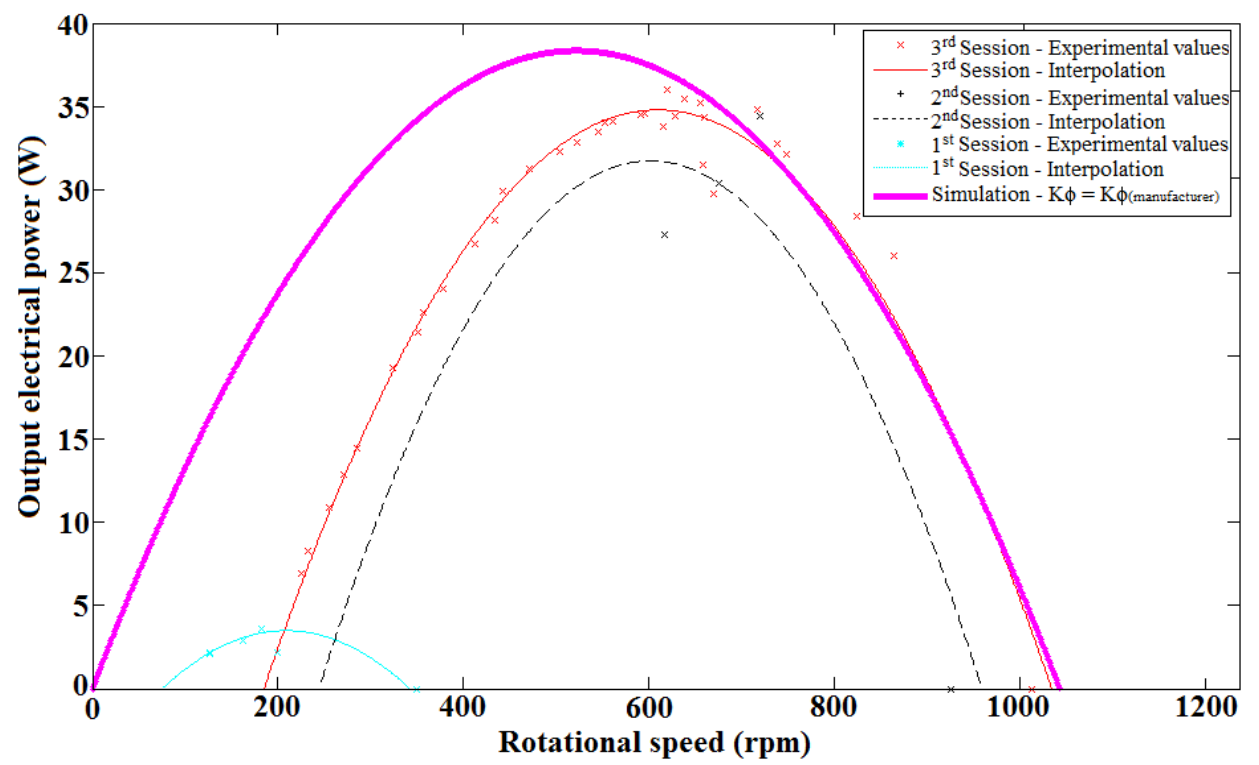

Fig. 9. Simulation and experimental turbo-generator group Output power/Speed curves

\section{Conclusions and recommendations}

\subsection{Pump as Turbine}

\subsubsection{Main conclusions}

From the power generation testing results, it is possible to conclude that the application of PATs for micro-hydro generation in water supply systems is viable. However, using gridconnected excitation may not be viable in all cases, namely the ones regarding lower power values. Control methods using valves, although efficient, may not be viable, namely in situations where there's a generation scheme directly applied to the main piping. In these cases, reducing the water flow, for control purposes, in hours of greater water need, may be prejudicial for the populations.

\subsubsection{Recommendations}

To avoid the excitation related issues, and according to [2] and [11], using "motor run" capacitors (either star, delta, or C-2C connected) for excitation purposes is an alternative, and more efficient way, than resorting to the main grid. As mentioned, for main piping connected 
generation schemes, control methods using ELCs, or other electronic devices, may eliminate the issues related with control methods using valves.

\subsection{Five blade propeller turbine}

\subsubsection{Main conclusions}

Despite the power values that were generated, the 5BPT, regarding its use in water supply systems, is a very promising solution, with high hydro-mechanical efficiency values. The generated power values using the DC machine, although low, are still viable in a battery charging, or in a low power consumption equipment supply context. The turbo-generator group, when applied to water supply systems, doesn't interfere with the normal flow behavior in the piping.

\subsubsection{Recommendations}

Regarding power generation in a real system (opposed to a laboratorial one), for testing purposes, a permanent-magnet synchronous generator (or an induction motor) should be used. For laboratorial purposes, a lower power generator should be used, more adequate to the rotational speed and torque values present in the experimental piping system. Testing under better flow and head conditions, for improved power generation, is also recommended for future work.

\section{References}

[1] A. Williams, Pumps as Turbines: a user's guide, $2^{\text {nd }}$ Edition, Practical Action Publishing, 2003.

[2] H. Ramos, Guidelines for design of small hydropower plants, 2000, WREAN/DED, ISBN 972-96346-4-5.

[3] H. Ramos, A.B. Almeida, Dynamic effects in micro-hydro modeling, 2003, pp. Water Power \& Dam Construction, ISSN 0306-400X.

[4] H. Ramos, A.B. Almeida, Parametric analysis of waterhammer effects in small hydropower schemes, 2001, Journal of Hydraulic Research, IAHR, Vol. 39 (4), pp. 429436, ISSN-0022-1686.

[5] H. Ramos, A. Borga, Pumps as turbines: unconventional solution to energy production, Urban Water International Journal, Elsevier Science Ltd, 2000, pp.261-265.

[6] H.M. Ramos, A. Borga, M. Simão, New design solutions of low power for energy production in water pipe systems, Water Science and Engineering, 2009, 2(4): 69-84, doi:10.3882/j.issn.1674-2370.2009.04.007.

[7] H.M. Ramos, M. Mello, P. De, Clean power in water supply systems as a sustainable solution: from conceptual to practical analysis, IWA Publishing, Water Science and Technology, 2010.

[8] H.M. Ramos, F. Vieira, D. Covas, Energy efficiency in a water supply system. Water Science and Engineering, 2010, pp.331-340.

[9] J.S. Ramos, H.M. Ramos, Sustainable application of renewable sources in water pumping systems: optimized energy system configuration, 2009, ( doi:10.1016/ j.enpol. 2008.10.006), Energy Policy 37, 633-643.

$[10] N$. Smith, Motors as generators for micro-hydro power, $2^{\text {nd }}$ Edition, Practical Action Publishing, 2008. 